Round 1 Time from invitation to test package request

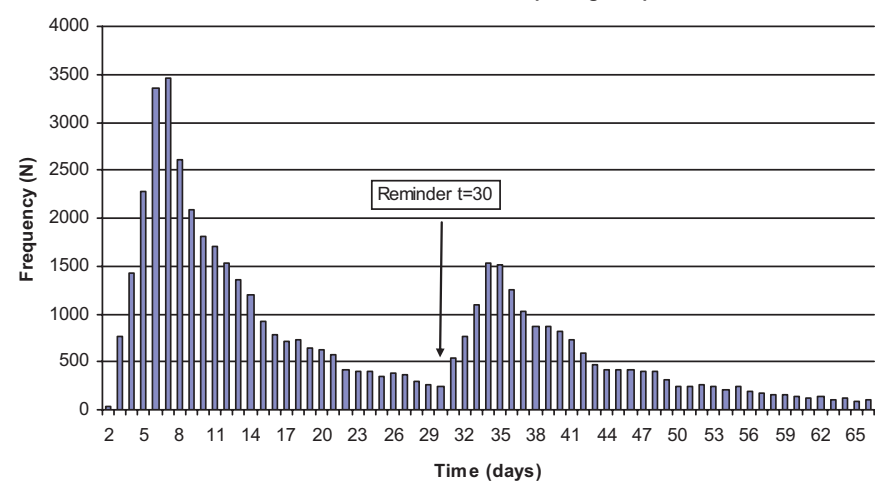

Abstract P2-S8.07 Figure 1 Round 1time from invitation to test package request.

\section{P2-S8.08 REDUCING THE STIGMA OF HERPES SIMPLEX VIRUS (HSV) INFECTION THROUGH BRIEF PUBLICLY-GENERATED VIDEOS}

doi:10.1136/sextrans-2011-050108.382

${ }^{1}$ L S Shearer, ${ }^{2} \mathrm{~L}$ W Simmons, ${ }^{3} \mathrm{~A}$ Mindel, ${ }^{2} \mathrm{~L}$ R Stanberry, ${ }^{2} \mathrm{~S}$ L Rosenthal. ${ }^{1}$ New York Presbyterian Hospital, Columbia University Medical Center, New York, USA; ${ }^{2}$ Columbia University, New York, USA; ${ }^{3}$ University of Sydney, Sydney, Australia

Background Herpes simplex virus (HSV) is one of the most prevalent sexually transmitted infections worldwide. The stigma associated with HSV infection remains problematic and may lead to negative psychological sequelae and delayed care-seeking. Media technology is an innovative tool for countering stigma. Publicly-produced media content is not well-studied in this context, but may offer key lessons on successful de-stigmatising strategies.

Methods The Australian Herpes Management Forum and Novartis organised an online contest inviting the public to develop brief videos to de-stigmatise HSV. In the present study, content analysis was performed to identify de-stigmatising strategies employed in the videos. Two researchers independently coded each video and resolved discrepancies by consensus with a third coder.

Results Of 113 videos, 11 were excluded from analysis because they did not mention HSV, provided inaccurate information, or had no identifiable strategy. Five de-stigmatising strategies emerged from review of the remaining videos: normalising through familiarity, providing knowledge or fostering knowledge-seeking, expressing moral indignation, promoting disclosure, and negating a negative perception. Despite employing one or more of these strategies, many videos did not successfully de-stigmatise HSV infection. Coders perceived just over half of the videos as de-stigmatising but the remainder as stigmatising, neutral, or mixed. Most de-stigmatising videos shared two important characteristics: 1) they employed familiarity" as a strategy and 2) they acknowledged actual negative aspects of HSV infection but offered a successful positive counterpoint. Stigmatising videos did not offer sufficiently positive counterpoints. Neutral videos were primarily informational. Mixed videos had strong stigmatising and de-stigmatising messages. One barrier to success was communicating important negative information (such as symptomatology or transmissibility of HSV) without stigmatising the disease.

Conclusions The results emphasise that de-stigmatising HSV infection is difficult. Simultaneously acknowledging negative aspects of HSV infection while providing a sufficiently strong positive counterpointespecially by promoting familiarity-may represent a key element in developing effective media campaigns to counter HSV stigma. Future research should evaluate the hypotheses generated in this study in target audiences such as those infected with HSV and members of the public.

\section{P2-S8.09 WHAT ARE THEY ASKING? AN ANALYSIS OF STD RELATED CALLS TO CDC-INFO}

doi:10.1136/sextrans-2011-050108.383

${ }^{1} \mathrm{R}$ Kachur, ${ }^{2} \mathrm{~N}$ Thompson, ${ }^{2} \mathrm{~S}$ Haecker, ${ }^{2} \mathrm{R}$ Jones. ${ }^{1}$ Centers for Disease Control \& Prevention, Atlanta, USA; ${ }^{2}$ CDC, USA

Background Launched in 2005, CDC-INFO is the Center for Disease Control and Prevention's (CDC) national contact center, which responds to health related enquiries from the general public and healthcare providers and partners $24 \mathrm{~h}$ a day, 7 days a week. STDrelated topics have consistently been among the top ten most frequently asked questions. In order to better understand what information is being sought, telephone calls and emails to CDCINFO were analysed for STD specific topics and topic frequencies.

Methods STD-related calls and emails made to CDC-INFO between October 2009 and September 2010 (FY2010) were analysed for topic content and frequency.

Results In FY2010, there were 44339 STD-related calls and 2123 STD-related emails to CDC-INFO. Enquiries fell into 11 main categories. The top 3 telephone enquiries were about Herpes (26\%), Testing and Counselling (25\%) and Human Papillomavirus (HPV) (18\%). The top 3 email enquiries were about Herpes (34\%), HPV (21\%) and Other Sexually Transmitted Diseases (12\%). The most common STD question to CDC-INFO was Can you help me locate a STD testing site in my area?", although the largest percentage of questions were about Herpes, followed by HPV, Testing and Counselling and Chlamydia. Findings from CDC-INFO correlate with findings from traffic to the Division of STD Prevention (DSTDP) website (http://www.cdc.gov/std/) which also finds that Genital Herpes and HPV are the most frequently visited pages on the website. A CDC-INFO satisfaction survey conducted between October 2009-and March 2010 found that among STD related telephone callers, $63 \%$ were female, over $65 \%$ were 34 years old or younger, $34 \%$ were White and $35 \%$ were Black/African American. Of those qualitatively interviewed, 91\% $(n=199)$ reported learning new information as a result of the call to CDC-INO and $68 \%$ indicated a desire to change a behaviour based on the new information. Reducing risky sexual behaviour was the most common type of behaviour change indicated.

Conclusions Information about Genital Herpes, HPV, and STD testing locations are the most frequently sought after topics by those accessing CDC-INFO. Regularly analysing enquiries to CDCINFO can help the DSTDP identify topics of most concern to the general public, possibly detect emerging trends and tailor communications accordingly. Further research should be done to determine how DSTDP communication and prevention priorities correspond to general public enquiries and concerns.

\section{P2-S8.10 MEASURING SOCIAL MEDIA EFFORTS: BEYOND CLICK THROUGHS}

doi:10.1136/sextrans-2011-050108.384

${ }^{1} \mathrm{R}$ Kachur, ${ }^{1} \mathrm{~L}$ Richman, ${ }^{1} \mathrm{M}$ Hable, ${ }^{1} \mathrm{R}$ Verma, ${ }^{1} \mathrm{~A}$ Friedman, ${ }^{1} \mathrm{C}$ Kapsimalis, ${ }^{1} \mathrm{M}$ McFarlane, ${ }^{2} \mathrm{~A}$ Patel. ${ }^{1}$ Centers for Disease Control \& Prevention, Atlanta, USA; ${ }^{2}$ Planned Parenthood Federation of America, USA

Background With the rapid expansion of social media, public health organizations have been quick to adopt these new channels to reach target populations. Typically, however, these efforts are accompanied by minimal evaluation and results are not routinely used to inform and improve programs. The GYT: Get Yourself Tested campaign, a national, US campaign to increase STD testing and decrease stigma is a case study that illustrates the challenges and the importance of evaluating social media. 